\title{
How does community service promote prosocial behavior? Examining the role of agency and ideology experience
}

\author{
Gabriela Christoph, ' Burkhard Gniewosz, ${ }^{2}$ and Heinz Reinders ${ }^{3}$
}

\begin{abstract}
This study examines community service effects on adolescents' prosocial behaviors as mediated through experiences made during service. Based on theoretical assumptions by Youniss and Yates, we suggest that personal agency experiences and being confronted with situations that can challenge the own world views (ideology experiences) serve as mediators. The data were collected in a two-wave longitudinal study surveying 2,408 German adolescents aged between 14 and 15 years. Based on true intraindividual change models, the results support the expected mediation of service effects on prosocial behaviors through agency, but not ideology experiences. The findings suggest that community service affects prosocial behaviors through a behavioral pathway.
\end{abstract}

\section{Keywords}

Adolescence, agency, community service, ideology, prosocial behaviors

*This article accepted during Marcel van Aken's term as Editor-in-Chief.

Adolescence is a time of major changes in various developmental domains. Young people start to think about who they are and how to live their lives. Together with these major steps in identity development (Harter, 2006; Kirshner, 2009; Luyckx, Goossens, Soenens, $\&$ Beyers, 2006), there are also crucial changes in adolescents' prosocial behaviors (e.g. Eisenberg, Fabes, \& Spinrad, 2006). From a Positive Youth Development (PYD) perspective (e.g. Scales, Roehlkepartain, Neal, Kielsmeier, \& Benson, 2006; Sherrod, 2007), external developmental assets have the potential to trigger identity and behavioral changes in adolescents. Participation in community service is one opportunity for structured and supervised leisure activities (Eisenberg et al., 2006, for German adolescents Gensicke \& Geiss, 2010). Therefore, community service can be seen as an important contextual asset for adolescent development and thus as an important context fostering prosocial behaviors. Nevertheless, the processes how community service can promote adolescents' positive development, e.g. prosocial behaviors, are hardly understood. Based on the theoretical ideas by Youniss and Yates (1997), the present study focuses on the processes linking community service and prosocial behaviors.

\section{Theoretical framework explaining service effects}

As proposed in PYD theorizing, community service is seen as an external asset for the development of prosocial behaviors and shall serve as explanatory variable for prosocial behaviors in this study. A very broad definition of community service involves " ... activities dedicated to the welfare of others or to society in general" (Magen \& Aharoni, 1991, p. 127). Thus, community service does not exclusively address individual people in need, but also involves the focus on the society. Therefore, a direct contact with people in need is not necessarily part of it. Moreover, a major share of German adolescents' community service activities takes place in a non-organizational and rather project-based context (Picot \&
Geiss, 2007). Thus in Germany, community service does not necessarily take place in an organizational framework.

In the literature, two kinds of models on community service are proposed. First, there are models focusing on the determinants of being engaged in community service (e.g. Marta \& Pozzi, 2008; Penner, 2004; Snyder \& Omoto, 2007). Second, and for the present study of greater relevance, there are models on how community service can affect youth development. Youniss and Yates (1997) formulated a theoretical model linking the experiences made during community service to developmental outcomes. Adolescents may get in contact with people in need that are not part of their everyday lives and may learn about their lives and biographies as well as the circumstances that have led to their precarious life situations. Furthermore, even when there is no such direct contact with people in need, adolescents may find themselves in situations broadening their perspectives on living together in a society, for instance during service in an environmental project or a political campaign. Moreover, youths' service activities can take place within a structured or organized context (Penner \& Finkelstein, 1998). Those organizations running service activities often provide a certain set of world views that serve as rationales for attending service (Youniss \& Reinders, 2010; Youniss \& Yates, 1997).

One major goal of this study is to predict adolescents' prosocial behaviors. Marta and Pozzi (2008, see also Penner, 2004) identified three conceptually different approaches: 1) prosocial behaviors as

\footnotetext{
I German Institute for International Educational Research, Germany

2 University of Munich, Germany

${ }^{3}$ University of Wuerzburg, Germany
}

\section{Corresponding author:}

Gabriela Christoph, German Institute for International Educational Research, Schloßstraße 29, D 60486 Frankfurt am Main, Germany.

Email: christoph@dipf.de 
spontaneous, short-term, and unplanned actions in favor of an unknown person in direct contact, 2) prosocial behaviors as longterm and continuing assistance to family members or close relatives, and 3) prosocial behaviors as volunteerism, defined as sustained, planned actions benefiting strangers within an organizational setting. The present study aims to explain the first form of prosocial behaviors.

Research in regards to demographic background variables that should be considered as potential covariates showed differences in prosocial behavior and community service due to gender and educational background. Wilson and Musick (1997) showed that women rated altruism, empathy, and helping behavior as more valuable than men did. Furthermore, girls generally seem to be more likely than boys to report feelings of compassion and a stronger sense of being responsible for caring for others in need (Flanagan, Bowes, Jonsson, Csapo, \& Sheblanova 1998; Gensicke, 2005). Moreover, community service participation is strongly associated with the level of education and family-income (Kuhn, Uhlendorf, \& Krappmann, 2000; Marzana et al. 2012). For instance, in a German study, young people attending a higher school track were more likely to do voluntary work than were students from a lower school track (Gensicke, 2005).

Youniss and Yates (1997) emphasize two important experiences that adolescents can make during community service: ideology and agency experiences. Ideology experiences are those experiences that have the potential to change the adolescents' personal beliefs about how the world works, how the social system is organized, and how one's role in the world is defined, which Erikson (1968) called ideology. Harter's (2006) concept of self-portrait, as a cognitive and social construction about the world and oneself, can be linked to this idea. Especially during adolescence, changes in these selfportraits are proactively driven by the adolescents themselves as well as by external social influences (Harter, 2006; Kirshner, 2009). During community service, adolescents have the opportunity to make so called ideology experiences that help them to construe a convincing world image, positioning themselves in a larger societal context (Erikson, 1968; McIntosh, Metz, \& Youniss, 2005).

Moreover, during the majority of community service activities, adolescents can learn that they can actually provide a valuable contribution to a good cause. They can attribute the results of their actions internally and, thus, develop positive perceptions of their capabilities. Therefore, community service provides an opportunity for adolescents to experience that they can efficaciously and positively affect their environment. This concept of perceived agency is conceptually close to Bandura's concept of self-efficacy (2001). According to Youniss and Yates (1997), experiences that enable the adolescents to feel efficacious, are called agency experiences.

Following Youniss and Yates (1997), these experiences trigger a process of identity changes. This process is called transcendence and involves three dimensions (see Figure 1). The term transcendence describes the process of shifting the egocentric focus of oneself towards a more interconnected self (Furrow \& Wagener, 2003; Yates \& Youniss, 1998). First, service triggers a process of reflecting on or rethinking one's stereotypes and attitudes. Adolescents start reconsidering their beliefs against the backdrop of the experiences they made during service. Second, Youniss and Yates (1997) suggest that adolescents gain a new perspective on their own lives and a higher sense of social responsibility due to their service experiences. These changed perspectives, as well the agency experiences during community service, trigger a feeling of having

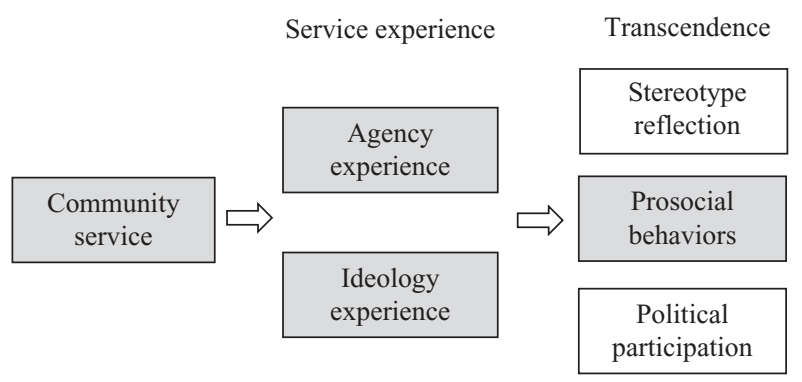

Figure I. Theoretical model of community service.

Note. The grey boxes mark the variables considered in the present study.

the power and the responsibility of making a difference for the benefit of the society, leading to an increased willingness to engage in prosocial behaviors. Third, young people should start thinking about their own life as being part of a larger society and start reasoning about social problems and societal injustices. In order to find solutions the willingness to political participation should be enhanced.

\section{Empirical status of Youniss' and Yates' model on community service}

In the following section we shortly summarize findings concerning adolescents' prosocial behaviors and community service activities. According to Yates' and Youniss' (1996) review, adolescents who engaged in community service were more socially-oriented than adolescents who were not engaged. More recent research showed that participating in community service is positively associated with a prosocial development (Carlo, Okun, Knight, \& de Guzman, 2005; Metz, McLellan, \& Youniss, 2003; Youniss \& Reinders, 2010), helpfulness, other-oriented empathy (Penner \& Finkelstein, 1998), prosocial value motivation (Carlo et al., 2005), social responsibility (Scales, Blyth, Berkas, \& Kielsmeier, 2000), and prosocial norms (Hansen, Larson, \& Dworkin, 2003). One of the few published longitudinal studies reported positive effects of community service on adolescents' prosocial behaviors over time (Reinders \& Youniss, 2006). Janoski, Musick, and Wilson (1998) showed that voluntary work undertaken in high school facilitated prosociality above and beyond school age.

Another line of research has provided evidence for the suggested processes involved in community service participation effects on prosocial behaviors. In their qualitative study on community service, Youniss and Yates (1997) concluded that the agency and ideology experiences as well as instructed discussions and reflections on the experiences contributed to adolescents' willingness to helping behaviors. From the authors' perspective, adolescents' ideologies were challenged by getting in contact with people in need as well as by working on behalf of an organization's rationale during community service. Moreover, students learned that they can actually provide support for people in need, resulting in the experience of being self-efficacious. Reinders and Youniss (2006; Youniss \& Reinders, 2010) presented longitudinal evidence in an American sample, showing that different types of service (interaction with people in need vs. no interaction) affected helpfulness in different ways, depending on the experiences the adolescents made. This was supported by parallel cross-sectional analyses in a German sample (Youniss \& Reinders, 2010). 


\section{The present study}

Previous research already showed the relationship between service and several outcomes. Nevertheless, mechanisms and processes leading to these relations are hardly understood or tested. The present study examines the effects of community service (vs. no service) on prosocial behaviors in adolescence. To our knowledge, no systematic longitudinal quantitative empirical analysis has been conducted testing the mediation assumptions formulated by Youniss' and Yates' (1997). Thus, we investigate the role of agency and ideology experiences in explaining the effect of community service on prosocial behaviors. We expect an indirect effect of being engaged in community service on prosocial behaviors via agency and ideology experiences. Adolescents who are active in service are expected to make more experiences regarding their own efficacy (agency experiences) and with situations that might change their ideologies (ideology experiences) than adolescents who are not engaged in community service. Agency and ideology experiences should subsequently be linked to more prosocial behaviors. In all analyses, the effects of potential confounders (gender and school track) are controlled.

The present study goes beyond the existing literature in several ways. First, this longitudinal study allows for testing the direction of effects between community service and prosocial behaviors. Second, the indirect effect of community service on prosocial behaviors through agency and ideology experiences was never tested comprehensively. Third, the theoretical model by Youniss and Yates (1997) is mainly based on a qualitative study. The present study aims to test the assumptions in a quantitative study. Finally, most research in this field was conducted in the US. In order to test the model's assumptions in a more general way, we use a representative German sample. In Germany, there is only voluntary and no required community service. This is one reason why community service in adolescence is more common in the USA than in Germany (Hofer, 1999). If the theoretical assumptions hold in this different social context, the support of the proposed processes is much stronger.

\section{Method}

\section{Sample}

The analyses presented here used data from the longitudinal research project Youth. Engagement. Political Socialization (Reinders, 2014). The main goal of this project is to investigate effects of participating in community service on adolescents' social development using a nationally-representative sample of 14-15-year-olds and following them on a yearly basis. The data was collected through computer-based telephone interviews, which is a timely and cost-efficient method to survey large and representative samples with the necessary geographical coverage (Bennett \& Steel, 2000). The sample is a stratified random sample (by gender and school track) drawn from the data of the federal registry offices. Adolescents without informed parental consent and those who were unable to participate due to limited German language skills, emotional or intellectual handicaps were excluded. One year later, the adolescents were contacted again for a second wave.

At the first wave of data collection, 2,408 adolescents were interviewed (46.9\% female; mean age: $M=14.50, S D=0.50$, age range: 14-15). Formal achievement-based tracking characterizes the organization of high schools in Germany, offering three major school tracks, namely a high track ("Gymnasium"), a middle track ("Realschule"), and a low track ("Hauptschule"). The latter two tracks were merged into one category in this study, because in Germany, community service rates and effect patterns seem not to differ between these tracks (Gensicke, 2010). Of the adolescents, $50.7 \%$ attended the highest school track and $49.3 \%$ attended lower school tracks. At the second wave of data collection, 1,825 adolescents participated ( $49.1 \%$ female; mean age: $M=15.51, S D=0.58$, age range: $14-17 ; 53.5 \%$ attended the highest school track). The participants were predominantly from an ethnic German background $(84.5 \%)$. All participants were interviewed by using the same standardized interview at $\mathrm{T} 1$ and $\mathrm{T} 2$.

\section{Measures}

Community service was measured along two steps at both measurement points: First, participants were asked if they were "... voluntarily active for other people or a good cause" at that (actual) time or during the last 12 months. In a second step, the adolescents were asked to name all those activities they actually do or did in the last year in that respect. This well-established method was chosen to prevent an underestimating of the community service rates (Kuenemund, 2006). The resulting pool of activities was coded in regards to the above described definition of community service by three raters, following the criteria a) planned action, b) longevity or repeated action, c) helping behavior outside the family. According to our definition, and in contrast to Penner (2004), we intentionally included community work within and without an organizational context taking into account that service activities in Germany can take place in rather informal projects and initiatives (Beher, Liebig, \& Rauschenbach, 1999; Picot \& Geiss, 2007; Reinders \& Youniss, 2006). This second step prevented an overestimation of service rates (Kuenemund, 2006). Examples of community service activities are given in the Appendix.

To ensure that all adolescents focus on the same time period regarding their activities and experiences, we employed the adolescents' reports collected at the second measurement occasion. Then, a dichotomous variable was created contrasting adolescents who were not involved in community service in the last year, measured at T2 $(n=900,49.3 \%)$, to adolescents who were $(n=925$; $50.7 \%$ ). Compared with national statistics of 14-16-year-olds, the community service rate in this sample is somewhat larger (36\%-38\%; Gensicke \& Geiss, 2010). This might be due to different operationalizations of community service. On the international level, the community service rate in this sample is about average (Flanagan et al., 1998: raging between $16 \%$ and $68 \%$ ).

Prosocial behaviors, defined as helping behaviors toward unknown people in everyday life, was measured by six items (Penner, Fritzsche, Craiger, \& Freifeld, 1995; German adaptation by Reinders, 2006), using a four-point rating scale ( $1=$ never to $4=$ very often). The reliability of the scale is sufficient (Cronbach's $\alpha$ : $\mathrm{T} 1=.74 ; \mathrm{T} 2=.80$ ). The items represent the self-reported helpfulness component of the original measurement by Penner et al. (1995). ${ }^{1}$

Agency experiences, defined as the experience of personal effectiveness resulting from own actions, was also measured by six items (Reinders, 2005; Reinders \& Youniss, 2006), using a four-point rating scale $(1=I$ do not agree at all to $4=I$ totally agree $)$. The reliability of this scale was good (Cronbach's $\alpha$ : T1 $=.80 ; \mathrm{T} 2=.90$ ). 
The second mediator, ideology experiences, as the experience of changes in one's self-portrait was also measured by six items (Reinders, 2005; Reinders \& Youniss, 2006) on a four-point scale $(1=I$ do not agree at all to $4=$ I totally agree). The reliability of the scale was good (Cronbach's $\alpha$ : T1 $=.82 ; \mathrm{T} 2=.86$ ).

A complete list of items is presented in Table A1, in the Appendix. Agency and ideology experiences were reported by all adolescents using the same wording. For those who were active in community service, the questions referred to the experiences during service. The others were asked to think about free-time activities while responding. Those two groups were identified in the first step of the measurement of community service. The computer-assisted survey was adapted to the answer on that question.

\section{Analyses}

All analyses were conducted using structural equation modeling techniques with Mplus 6.1 (Muthén \& Muthén, 2010). Missing data were handled by the full information likelihood algorithm. Thus, cases with missing data were not excluded, but all model parameters were estimated based on the cases with complete data and the (conditional) missing values under the missing at random assumption. As compared to listwise deletion, this procedure does not lead to the common disadvantages, such as losing statistical power or biased parameter estimation (Graham, 2009). Missing data on all variables proved to be completely at random, Little's MCAR test (R. Little, 1988): $\chi^{2}(17)=14.13, p=.66$.

To exploit the full potential of the longitudinal data set, True Intraindividual Change (TIC) models were applied (Steyer, Partchev, \& Shanahan, 2000). The basic modeling idea of this approach is depicted in Figure 2. The variable of interest is measured by two item parcels for each time point $\left(\mathrm{Y}_{11}, \mathrm{Y}_{21}\right.$ at $\mathrm{T} 1$ and $\mathrm{Y}_{12}, \mathrm{Y}_{22}$ at $\left.\mathrm{T} 2\right)$. The time 1 manifest variables $\left(\mathrm{Y}_{11}, \mathrm{Y}_{21}\right)$ are explained by one latent intercept variable and an error term. The time 2 manifest variables $\left(\mathrm{Y}_{12}, \mathrm{Y}_{22}\right)$ are explained by the latent intercept and the change variables (plus error term). Therefore, the meaning of the first latent variable is the baseline measurement at the first point of measurement. Through this measurement model, the variances of the T2 manifest measures splits of into intercept and change variance. Hence, the second latent variable represents the change variance between measurement occasions. In order to secure the same meaning or metric of the latent variables the loadings for each item parcel are set equal across the latent variables. The major advantage of this approach over cross-lagged analyses is that true latent mean changes in the construct are modeled. Simply spoken, with those analyses it is possible to predict the interindividual variance in latent means (intercepts) and the interindividual variance in the latent mean changes over time. In standard crosslagged analyses, however, only rank-order changes between measurement occasions are modeled (Rogosa, 1995).

For both mediators (agency and ideology experiences) and the dependent variable (prosocial behaviors), baseline intercepts and latent change variables were specified using True Intraindividual Change models. For each construct two item parcels were created, using the item-to-construct balance approach (T. D. Little, Cunningham, Shahar, \& Widaman, 2002). In the error covariance matrix of the manifest variables, the diagonal and the covariances between the error terms of those manifest variables referring to

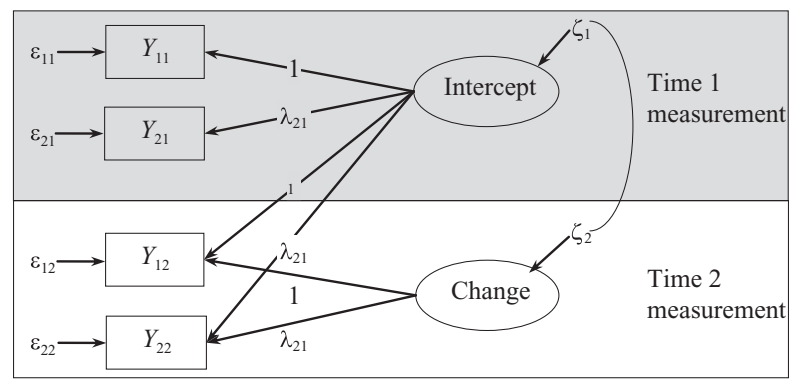

Figure 2. Schematic true individual change model.

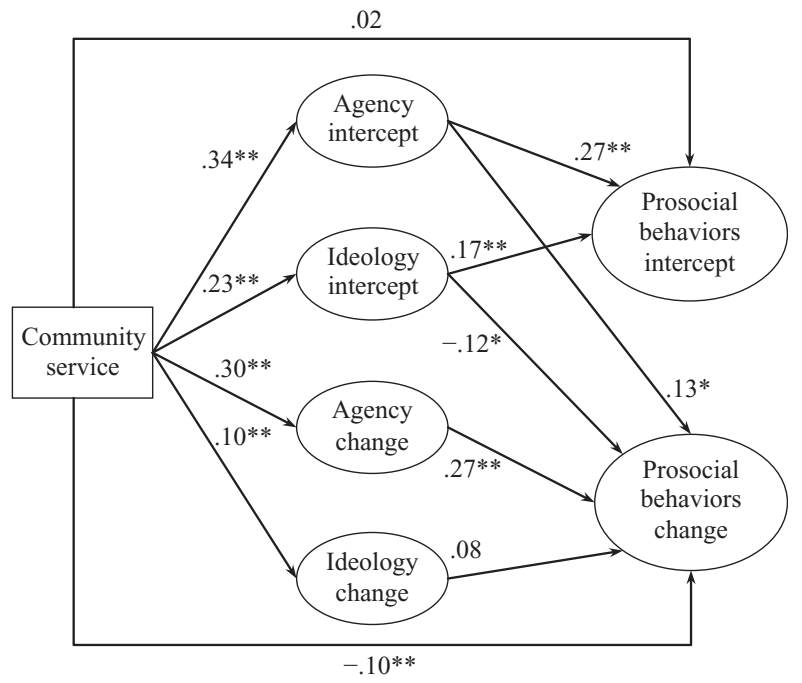

Figure 3. Mediation model.

Note. Standardized regression coefficients are represented $(n=2,408)$. $* p<.05 ; * * p<.01$.

parallel item parcels across measurement occasions were estimated to control for measurement variance (see correlated uniqueness; Marsh, Byrne, \& Craven, 1992).

In a first step, a descriptive model was specified. Here, only the six latent variables were estimated (no controls, no predictions) to obtain the unadjusted latent means and variances of the constructs. In a second step, the mediation model was tested. All six latent variables (intercepts and changes in the mediators and the dependent variable) were predicted by the dichotomous community service variable $(1=$ no service, $2=$ service $)$ as well as the control variables school track $(1=$ low, $2=$ high $)$ and gender $(1=$ male, $2=$ female $)$. The intercept of the adolescents' prosocial behaviors was predicted by the intercepts of the mediators. The changes in prosocial behaviors were regressed on both the intercepts and the changes of the mediators. Thus, there is a time-lagged prediction of the dependent variable, controlled for contemporaneous effects of the changes in the mediator variables. The mediation model is presented in Figure 3.

All correlations between the intercepts and changes for the same construct as well as all correlations between the intercepts and changes of the mediators were estimated. In this mediation model, the estimates of the total (effects of the independent on the dependent variable without considering the mediators), the direct (effects of the independent on the dependent variable controlled for mediator effects), and the indirect effects (effects of the independent on 
Table I. Results of the descriptive model.

\begin{tabular}{|c|c|c|c|c|c|}
\hline & $M$ & $p$ & $S^{2}$ & $S D$ & $p$ \\
\hline \multicolumn{6}{|c|}{ Agency experiences } \\
\hline Intercept & 2.69 & $<.001$ & 0.53 & 0.73 & $<.001$ \\
\hline Change & -0.05 & $<.01$ & 0.51 & 0.71 & $<.001$ \\
\hline \multicolumn{6}{|c|}{ Ideology experiences } \\
\hline Intercept & 2.20 & $<.001$ & 0.35 & 0.59 & $<.001$ \\
\hline Change & -0.07 & $<.01$ & 0.33 & 0.57 & $<.001$ \\
\hline \multicolumn{6}{|c|}{ Prosocial behaviors } \\
\hline Intercept & 3.22 & $<.001$ & 0.22 & 0.47 & $<.001$ \\
\hline Change & 0.07 & $<.001$ & 0.15 & 0.39 & $<.001$ \\
\hline
\end{tabular}

Note. $n=2,408$. All variables are rated on a 4-point Likert scale, ranging from I to 4. Higher scores indicate more of that quality.

the dependent variable via the mediators) were obtained through the MODEL INDIRECT option in Mplus. For testing the mediation on statistical significance bootstrapping methods were applied (MacKinnon, 2008). We used 10,000 resampling cycles in order to yield distribution estimates for all model parameters. A $95 \%$ confidence limit was used to determine the significance of the indirect effect. If the zero is not included in this interval, the indirect effects can be considered as statistically significant. Please note, that a statistically significant total effect is not necessary for the interpretation of indirect effects (e.g. MacKinnon, Krull, \& Lockwood, 2000; Shrout \& Bolger, 2002).

\section{Results}

\section{Descriptive results}

The descriptive model showed a good fit to the data, $\chi^{2}(36, n=2,408)$ $=90.77, p=.03 ;$ RMSEA $=.03$, SRMR $=.01 ; \mathrm{CLI}=.99$; TLI $=.99$. The means and variances of the latent variables are depicted in Table 1. The mediators showed small, yet significant, decreases over time, while the dependent variable slightly increased. Adolescents reported less agency and ideology experiences and more prosocial behaviors at T2. More interestingly, the variances $\left(s^{2}\right)$ of the intercepts and changes were significantly different from zero. Thus, there is substantial interindividual variation that can be explained.

\section{Main analyses}

The mediation model fitted the data well, $\chi^{2}(56, n=2,408)=$ $192.15, p<.001 ; \mathrm{RMSEA}=.03, \mathrm{SRMR}=.02 ; \mathrm{CLI}=.99$; $\mathrm{TLI}=.98$. The latent intercorrelations of the variables can be taken from Table 2. The regression coefficients are reported in Table 3 and Figure 3. There were a few predictions by control variables. Boys reported stronger changes in their agency experiences than girls $(\beta=-.07 * *)$. The general level of ideology experiences was higher for girls than for boys $\left(\beta=.06^{* *}\right)$, so was the level of prosocial behaviors $\left(\beta=.09^{* *}\right)$. Adolescents attending the lower school track reported higher levels of ideology experiences than students from the higher school track $\left(\beta=-.10^{* *}\right)$.

Supporting our first expectation, being active in community service during the last 12 months positively predicted the intercepts and slopes of both mediators. As compared to adolescents who were not involved in service, those who were reported higher levels of agency $\left(\beta=.34^{* *}\right)$ and ideology experiences at T1 $\left(\beta=.23^{* *}\right)$ as well as stronger changes in both variables between the measurement occasions (agency experiences: $\beta=.30^{* *}$; ideology experiences: $\left.\beta=.10^{* *}\right)$.

Our second expectation stated that being active in community service is indirectly linked to prosocial behaviors through agency and ideology experiences. The way of longitudinal modeling that we applied allows for three possible indirect ways: 1) through linking the intercepts of the mediators and prosocial behaviors, 2) through linking the intercept of the mediators with changes in prosocial behavior, 3 ) through linking the changes in the mediators and the change in prosocial behaviors.

First, predicting the intercept of the adolescents' prosocial behaviors, the effects of both mediators' intercepts were significant, supporting our hypotheses (agency experiences: $\beta=.27^{* *}$; ideology experiences: $\left.\beta=.17^{* *}\right)$. The more agency and ideology experiences the adolescents made the more prosocial behaviors were reported. Inspecting the indirect effects of doing service on the intercept of prosocial behaviors indicated that the intercepts of agency and ideology experiences significantly mediated the service effects, indirect effects: through agency experiences: $\beta=.09 ; \mathrm{CI}=$ $(.076 ; .108)$, through ideology experiences: $\beta=.04, \mathrm{CI}=(.028$; .049 ). Thus, adolescents who were involved in service during the last 12 months made more agency and ideology experiences than adolescents not active in service, which, in turn, was linked to higher levels of prosocial behaviors.

Second, both intercepts of the mediators significantly predicted the changes in prosocial behaviors, across measurement occasions (agency experiences: $\beta=.13 * *$; ideology experiences: $\left.\beta=-.12^{* *}\right)$. The more agency the adolescents experienced, the stronger was the increase in prosocial behaviors over time. At the same time, a high level of ideology experiences was linked to a decrease in prosocial behaviors. The indirect effects of doing service on the changes in prosocial behaviors indicate that agency and ideology experiences significantly mediated the service effects, indirect effects: through agency experiences: $\beta=.04$; $C I=(.019 ; .067)$, through ideology experiences: $\beta=-.03$, $C I=(-.040 ;-.013)$. Adolescents who were involved in community service reported higher levels of agency and ideology experiences. In turn, those higher levels of agency experiences went along with an increase in prosocial behaviors, while higher levels in ideology experiences were linked to a decrease in prosocial behaviors.

Third, the changes in agency experiences positively predicted the change in prosocial behaviors $\left(\beta=.27^{* *}\right)$. These parallel changes over time mediated the effect of being involved in service, indirect effects: agency experiences: $\beta=.08 ; C I=(.063 ; .102)$. Adolescents who were actively involved in community service showed an increase in their agency experiences, which, in turn, was associated with an increase in the prosocial behaviors. There was no significant effect of the changes in the ideology experiences on the changes in prosocial behaviors.

In order to estimate the indirect effects, the residual direct effect of community service on prosocial behaviors has to be modeled. Predicting prosocial behaviors, there was no significant direct effect of doing service on the intercept $(\beta=.02)$ and a small negative direct effect of doing service on the change $\left(\beta=-.10^{*}\right)$. Controlled for the levels and changes in the mediators, adolescents who were active in service showed a small decrease in prosocial behaviors. The total effect of service on the intercept of prosocial behaviors was positive $(\beta=.15$, s.e. $=.03, p<.001)$, while the total effect of service on the changes in prosocial behaviors did not reach 
Table 2. Correlations of the variables.

\begin{tabular}{|c|c|c|c|c|c|c|c|c|c|c|}
\hline & & I & 2 & 3 & 4 & 5 & 6 & 7 & 8 & 9 \\
\hline I. & Community service & - & & & & & & & & \\
\hline 2. & Agency experiences intercept & $.34^{* *}$ & - & & & & & & & \\
\hline 3. & Agency experiences change & $.30 * *$ & $-.42 * *$ & - & & & & & & \\
\hline 4. & Ideology experiences intercept & $.22^{* *}$ & $.66 * *$ & $-.18^{* *}$ & - & & & & & \\
\hline 5. & Ideology experiences change & $.09 *$ & $-.22^{* *}$ & $.56 * *$ & $-.4 I^{* *}$ & - & & & & \\
\hline 6. & Prosocial behaviors intercept & $.16^{* *}$ & $.39 * *$ & $-.07 *$ & $.35 * *$ & -.05 & - & & & \\
\hline 7. & Prosocial behaviors change & .01 & $-.12^{* *}$ & $.22 * *$ & $-.15^{* *}$ & $.21^{* *}$ & $-.36 * *$ & - & & \\
\hline 8. & Gender & .04 & .05 & $-.05^{*}$ & $.06 *$ & -.04 & $.11 * *$ & .02 & - & \\
\hline 9. & School track & $.09 * *$ & .05 & .01 & $-.08 * *$ & .02 & .03 & .02 & .03 & - \\
\hline
\end{tabular}

Note. $n=2,408 . * p<.05 ; * * p$ < 01 . Community Service $(I=$ not involved in service, $2=$ involved in service $)$, gender $(I=$ male, $2=$ female $)$ and school track $(I=$ low, $2=$ high) are dichotomized variables. All other variables are rated on a 4-point Likert scale, ranging from I to 4 . Higher scores indicate more of that quality. The correlations are zero-order latent correlation obtained in Mplus. Correlations with regard to dichotomous variables (gender, community service, school track) are Point-biserial correlations. (In this special case, they are mathematically identical to Pearson correlations.)

Table 3. Results of the mediation model.

\begin{tabular}{|c|c|c|c|c|c|c|c|c|c|c|c|c|c|c|c|c|c|c|}
\hline & \multicolumn{6}{|c|}{ Agency experiences } & \multicolumn{6}{|c|}{ Ideology experiences } & \multicolumn{6}{|c|}{ Prosocial behaviors } \\
\hline & \multicolumn{3}{|c|}{ Intercept } & \multicolumn{3}{|c|}{ Change } & \multicolumn{3}{|c|}{ Intercept } & \multicolumn{3}{|c|}{ Change } & \multicolumn{3}{|c|}{ Intercept } & \multicolumn{3}{|c|}{ Change } \\
\hline & $\beta$ & s.e. & $p$ & $\beta$ & s.e. & $p$ & $\beta$ & s.e. & $p$ & $\beta$ & s.e. & $p$ & $\beta$ & s.e. & $p$ & $\beta$ & s.e. & $p$ \\
\hline Gender & .03 & .02 & .15 & $-.07^{*}$ & .03 & .01 & $.06 *$ & .03 & .02 & -.05 & .03 & .10 & $.09 * *$ & .03 & .00 & .05 & .03 & .13 \\
\hline School track & .02 & .02 & .50 & -.02 & .03 & .45 & $-.10 * *$ & .03 & .00 & .01 & .03 & .69 & .02 & .03 & .35 & .01 & .03 & .76 \\
\hline Community service & $.34 * *$ & .02 & .00 & $.30 * *$ & .02 & .00 & $.23^{* *}$ & .02 & .00 & $.10^{* *}$ & .03 & .00 & .02 & .03 & .39 & $-.10 *$ & .04 & .01 \\
\hline Agency experiences intercept & - & - & - & - & - & - & - & - & - & - & - & - & $.27^{* *}$ & .04 & .00 & $.13^{*}$ & .06 & .03 \\
\hline Agency experiences change & - & - & - & - & - & - & - & - & - & - & - & - & - & - & - & $.27^{* *}$ & .05 & .00 \\
\hline Ideology experiences intercept & - & - & - & - & - & - & - & - & - & - & - & - & $.17 * *$ & .04 & .00 & $-.12^{*}$ & .05 & .02 \\
\hline $\begin{array}{l}\text { Ideology experiences change } \\
R^{2}\end{array}$ & .12 & - & - & -09 & - & - & - & - & - & - & - & - & -18 & - & - & $\begin{array}{l}.08 \\
.09\end{array}$ & .05 & .11 \\
\hline
\end{tabular}

Note. $n=2,408 . * p<.05 ; * *_{p}<.01$. Community Service $(I=$ not involved in service, $2=$ involved in service), gender $(I=$ male, $2=$ female $)$ and school track $(I=$ low, $2=$ high) are dichotomized variables. All other variables are rated on a 4-point Likert scale, ranging from I to 4 . Higher scores indicate more of that quality. The coefficients are standardized regression coefficients obtained in Mplus.

significance $(\beta=.01$, s.e. $=.03, p=.85)$. The non-significant total effect of community service on changes in prosocial behavior might point to an inconsistent mediation (MacKinnon, Fairchild \& Fritz, 2007). ${ }^{2}$ The size or statistical significance of the total effects is not a necessary condition for a significant mediation (MacKinnon et al., 2000; Shrout \& Bolger, 2002). In this regard, the effects of the mediators and the indirect effects of the independent on the dependent variable are crucial. Taken together, the results support the expectations, that community service involvement is indirectly associated with the development of adolescent' prosocial behaviors as mediated through agency and ideology experiences made during the service activities.

\section{Discussion}

This study focuses on processes explaining community service effects on adolescents' prosocial behaviors. We argue that service may be a resource for adolescents' prosocial development. It provides the adolescents with opportunities to become engaged in the community as active agents for a good cause. Our results suggest that agency experiences play a substantial role as mediator of service effects on adolescents' prosocial behaviors. Adolescents doing service reported higher rates as well as an increase of feeling efficacious in helping others during the last 12 months, for instance by successfully supporting elderly people in their daily routines. Consequently, these agency experiences affected their prosocial development over time. The intercepts of agency experiences and prosocial behaviors were positively associated as well. These results support the expectations derived from Youniss' and Yates' (1997) model. Our interpretation is that adolescents start to perceive themselves as active agents and as being able to help others or serving a greater good during service activities. Consequently, these feelings affect the adolescents' prosocial behaviors outside their service. In the light of the social-cognitive theory (Bandura, 2001), one could speak of adolescents making mastery experiences while helping in the service context, which seems to generalize into everyday-life prosocial behaviors.

Based on Youniss' and Yates' (1997) model of community service, we expected a similar pattern of results for ideology experiences. The first step of the expected mediation was found. Adolescents who were engaged in service reported higher rates and increases of ideology experiences. For example, working in a service setting provided by a church or environmental organization, or interacting with adults who are also involved in service, could make adolescents think about their own value system. Thus, service provided a setting of experiences affecting adolescents' ideologies (Youniss \& Reinders, 2010; Youniss \& Yates, 1997). 
However, the transformation of these ideology experiences into increasing prosocial behaviors was not supported by our data. The intercepts of prosocial behaviors and ideology experiences were cross-sectionally associated. But this cannot be interpreted as directional link. In contrast, across time we found a negative effect of ideology experiences on the changes in prosocial behaviors. This surprising result is worth being investigated more closely, because not only the theoretical assumptions of Youniss and Yates (1997) but also some empirical findings suggest otherwise. So far, two explanations might help to focus future research directions. First, the finding of a negative indirect effect from community service to prosocial behavior through ideology experiences could indicate a methodological artifact. In case of small correlations, this kind of change modeling may lead to spurious negative associations (Steyer et al., 2000). Because the cross-time link is in fact very weak, one could follow the more cautious interpretation that service does not affect adolescents' prosocial behaviors through the ideology experiences. Second, if this contradictive effect is not methodological, it might depict a kind of reality check for adolescents who find themselves in service activities that are totally different from what they ever experienced or expected to get involved in. Following Kahne and Westheimer (2006), there might be a subgroup of adolescents who just recently started their service activities might in fact make ideology experiences, as indicated by the positive effect of service on ideology experiences. This means that their view of the world and themselves changed. Since the nature of the change is not tapped in the scales, this change can mean an initial deterioration of overly optimistic views when being confronted with the reality constraints of service. This initial drop in confidence and optimism after starting service can lead to disappointment during the first weeks or months of doing service and in turn to a decrease in prosocial behaviors. However, in our study we still found a positive correlation between the change in ideology experiences and the change in prosocial behaviors. This pattern could be indicative of a consolidation or an adaptation of the adolescents' expectations after doing service for some time. After a while, the more positive ideology experiences might foster prosocial behaviors, which would be reflected in a positive association in the changes in ideology experiences and prosocial behaviors over time. But clearly, more than two measurement occasions are necessary to test this interpretation.

An explanation for the different effect patterns in regard to the types of experiences can be that agency and ideology experiences, although related, differ in their nature (less than $50 \%$ shared variance). This study provided evidence for a behavioral pathway of service effects. Service affected prosocial behaviors through agency experiences. Both concepts are linked to behaviors. In our study, we found no clear pattern (across time, as well as between the change variables) suggesting effects of ideology experiences on prosocial behaviors. Ideology experiences are cognitive experiences and therefore might be rather linked to changes in cognitive outcomes. That could be regarded as a cognitive pathway. For example, several authors showed, that adolescents' beliefs, stereotypes, and their way of thinking changed during service (e.g. Watkins, Larson, \& Sullivan, 2007; Yates \& Youniss, 1998), which suggests cognitive changes. Thus, service effects might to operate through different pathways. This interpretation has to be tested in future research, linking agency and ideology experiences to behavioral and cognitive outcomes.

The present study links research on community service and positive development. Youniss' and Yates' (1997) model of community service emphasized the importance of the interconnection between positive development and the experiences during service. Service connects young people with the community and adults beyond family and school offering opportunities for joining ongoing community life (Kirshner, 2009). Speaking in a more general sense, it describes the relations between the individual (e.g. the volunteer) and a specific developmental context (community service) interacting in youth development. In positive youth development terminology (Lerner, Almerigi, Theokas, \& Lerner, 2005), being engaged in community service can be regarded as an external developmental asset that provides the individual with peer and adult support as well as developmental opportunities. Service seems to be an important framework to foster the indicators of positive youth development, known as the five Cs. Competence, can be enhanced by learning the skills needed for service, leading to Confidence when efficaciously applying those skills (agency experiences). Adolescents bond with people and institutions during service (Connection) and learn respect for the society and cultural rules (Character; ideology experiences). Finally, Caring and Compassion, in this study addressed as prosocial behaviors, are fostered through service. Thus, the present study aligns well with the positive youth development framework (Lerner et al., 2005).

Some limitations have to be kept in mind when interpreting the results. First, the study is limited to the age group of $14 / 15$ to $15 / 16$ year old adolescents. Thus, the results do not account for younger or older adolescents facing other developmental tasks. Second, all our variables were self-reports. Thus, it will be important to validate the result with, for instance, external ratings by coaches or parents on the experiences and prosocial behaviors. Third, our study focused on a specific part of the theoretical model on community service by Youniss and Yates (1997). Future research should be conducted to clarify the associations between participating in community service and the other dimensions of transcendence proposed by the model of community service. Fourth, factors that may mediate or moderate the effects were not tested in this study; for example, the duration of being involved in any service, if there were instructed reflection sessions, or the adolescents' commitment. Another moderator that would be fruitful to investigate is the type of service. If service activities include, for instance, direct contact with people in need in contrast to a more technical or environmental service might trigger a potential cognitive path to a greater extent than serve with no direct contact. Fifth, there might be third variables contributing to the link between community service and prosocial behaviors, e.g. prosocial personality (Penner \& Finkelstein, 1998), effects of family or peer contexts (e.g. Gaiser \& Rijke, 2006; Marzana, Marta, \& Pozzi, 2012), or other learning experiences across various social situations (e.g. Graziano, Habashi, Sheese, \& Tobin, 2007). It will be important to disentangle these multi-contextual contributions. A final limitation can be seen in the national focus on Germany. Although testing the validity of the theoretical model in another cultural context is important, the cultural invariance of processes can only be tested in multi-sample studies. 
Nevertheless, we conclude from that study that community service can positively affect adolescent prosocial development. This effects might operate through parallel pathways. In this study, we provided evidence for a behavioral pathway through agency experiences. Thus, in order to foster prosocial behaviors through community service, adolescents should be provided with the opportunity for such types of experience. When adolescents can learn that they actually make a difference during service, prosocial behaviors outside the service context can be enhanced.

\section{Funding}

This research was made possible by a grant to Heinz Reinders and Burkhard Gniewosz from the German Research Foundation: Re1569/6-1 (Reinders) and Re1569/6-2 (Reinders/Gniewosz).

\section{Notes}

1. Because the concepts of prosocial behavior and community service refer to "helping people in need," there is an overlap in the measures. To make sure that this overlap does not artificially inflate the subsequently reported results, the first item measuring prosocial behaviors (see Table A1 in the Appendix) was excluded in an additional analysis. The resulting model fit as well as the regression coefficients hardly differed. Therefore, we will present the results of the model including all items.

2. In regards to the negative direct effect of doing service on the change in prosocial behaviors, a significant positive total indirect effect $\left(\beta=.11^{* *}\right)$, i.e. the sum of the reported indirect effects and a significant negative direct effect $\left(\beta=-.10^{* *}\right)$ add up to a non-significant total effect $(\beta=.01)$.

\section{References}

Bandura, A. (2001). Social cognitive theory: An agentic perspective. Annual Review of Psychology, 52, 1-26. doi:10.1146/annurev. psych.52.1.1

Beher, K., Liebig, R., \& Rauschenbach, T. (1999). Das Ehrenamt in empirischen Studien - ein sekundäranalytischer Vergleich [Community Service in empirical studies - a secondary comparison]. Stuttgart, Berlin, Köln: Kohlhammer.

Bennett, D. J., \& Steel, D. (2000). An evaluation of a large scale cati household survey using random digit dialling. Australian \& New Zealand Journal of Statistics, 42(3), 255-270. doi:10.1111/ 1467-842X.00126

Carlo, G., Okun, M. A., Knight, G. P., \& de Guzman, M. R. T. (2005). The interplay of traits and motives on volunteering: Agreeableness, extraversion and prosocial value motivation. Personality and Individual Differences, 38(6), 1293-1305. doi:10.1016/j.paid.2004.08. 012

Eisenberg, N., Fabes, R., \& Spinrad, T. (2006). Prosocial development. In W. Damon \& R. M. Lerner (Eds.), Handbook of child psychology: Social, emotional, and personality development (pp. 646-718). New York, NY: Wiley.

Erikson, E. H. (1968). Identity and the life cycle: Selected papers. New York, NY: International University Press, Inc.

Flanagan, C. A., Bowes, J. M., Jonsson, B., Csapo, B., \& Sheblanova, E. (1998). Ties that bind. Journal of Social Issues, 54(3), 457-475. doi:10.1111/j.1540-4560.1998.tb01230.x

Furrow, J. L., \& Wagener, L. M. (2003). Editor's introduction: Identity and transcendence among youth: A view of the issues.
Applied Developmental Science, 7(3), 116-118. doi:10.1207/ S1532480XADS0703_1

Gaiser, W., \& Rijke, J. (2006). Gesellschaftliche und politische Beteiligung [Civil and political participation]. In M. Gille, S. G. W. Sardei-Biermann \& J. Rijke (Eds.), Jugendliche und junge Erwachsene in Deutschland [Adolescents and young adults in Germany] (Vol. 3, pp. 213-275). Wiesbaden, Germany: VS Verlag für Sozialwissenschaften.

Gensicke, T. (2005). Freiwilliges Engagement in Deutschland 1999-2004, Ergebnisse der repräsentativen Trenderhebung zu Ehrenamt, Freiwilligenarbeit und bürgerschaftlichem Engagement [Voluntary service in Germany 1999-2004, Results of a representative study on volunteering, voluntary work, and civic engagement]. Wiesbaden, Germany: VS Verlag für Sozialwissenschaften.

Gensicke, T. (2010). Monitor Engagement: Freiwilliges Engagement in Deutschland 1999-2004-2009 [Monitor engagement: Vouluntary service in Germany 1999-2004-2009]. Berlin, Germany: Publikationsverbund der Bundesregierung.

Gensicke, T., \& Geiss, S. (2010). Hauptbericht des Freiwilligensurveys 2009: Zivilgesellschaft, soziales Kapital und freiwilliges Engagement in Deutschland 1999-2004-2009 [Main report on the voluntary service study 2009: Civil society, social capital and voluntary service in Germany 1999-2004-2009]. Berlin, Germany: Bundesministeriums für Familie, Senioren, Frauen und Jugend.

Graham, J. (2009). Missing data analysis: Making it work in the real world. Annual Review of Psychology, 60(1), 549-576. doi:10. 1146/annurev.psych.58.110405.085530

Graziano, W. G., Habashi, M. M., Sheese, B. E., \& Tobin, R. M. (2007). Agreeableness, empathy, and helping: A person $\times$ situation perspective. Journal of Personality and Social Psychology, 93(4), 583-599. doi:10.1037/0022-3514.93.4.583

Hansen, D. M., Larson, R. W., \& Dworkin, J. B. (2003). What adolescents learn in organized youth activities: A survey of self-reported developmental experiences. Journal of Research on Adolescence, 13(1), 25-55. doi:10.1111/1532-7795.1301006

Harter, S. (2006). The self. In W. Damon \& R. M. Lerner (Eds.), Handbook of child psychology (pp. 505-570). New York, NY: Wiley.

Hofer, M. (1999). Community service and social cognitive development in German adolescents. In M. Yates \& J. Youniss (Eds.), Roots of civic identity (pp. 114-134). Cambridge, MA: Cambridge University Press.

Janoski, T., Musick, M., \& Wilson, J. (1998). Being volunteered? The impact of social participation and pro-social attitudes on volunteering. Sociological Forum, 13(3), 495-519. doi:10.1023/ a: 1022131525828

Kahne, J., \& Westheimer, J. (2006). The limits of political efficacy: Educating citizens for a democratic society. Political Science \& Politics, 1(2), 289-296. doi:10.1017/S1049096506060471

Kirshner, B. (2009). "Power in numbers": Youth organizing as a context for exploring civic identity. Journal of Research on Adolescence, 19(3), 414-440. doi:10.1111/j.1532-7795.2009. 00601.x

Kuenemund, H. (2006). Methodenkritische Anmerkungen zur Empirie ehrenamtlichen Engagements: Altern und bürgerschaftliches Engagement [Methodogical comments on the empiric assesment of community service]. In K. R. Schroeter \& P. Zängl (Eds.), Altern und bürgerschaftliches Engagement [Aging and community service] (pp. 111-134). Wiesbaden, Germany: VS Verlag für Sozialwissenschaften. 
Kuhn, H. P., Uhlendorf, H., \& Krappmann, L. (Eds.). (2000). Sozialisation zur Mitbürgerlichkeit [Civic socialization]. Opladen, Germany: Leske + Budrich.

Lerner, R. M., Almerigi, J. B., Theokas, C., \& Lerner, J. V. (2005). Positive youth development A view of the issues. The Journal of Early Adolescence, 25(1), 10-16. doi:10.1177/0272431604273211

Little, R. (1988). A test of missing completely at random for multivariate data with missing values. Journal of the American Statistical Association, 83(404), 1198-1202.

Little, T. D., Cunningham, W. A., Shahar, G., \& Widaman, K. F. (2002). To parcel or not to parcel: Exploring the question, weighing the merits. Structural Equation Modeling: A Multidisciplinary Journal, 9(2), 151-173. doi:10.1207/S15328007SEM0902_1

Luyckx, K., Goossens, L., Soenens, B., \& Beyers, W. (2006). Unpacking commitment and exploration: Preliminary validation of an integrative model of late adolescent identity formation. Journal of Adolescence, 29(3), 361-378. doi:10.1016/j.adolescence.2005. 03.008

MacKinnon, D. P. (2008). Introduction to statistical mediation analysis. Mahwah, NJ: Erlbaum Psych Press.

MacKinnon, D. P., Krull, J. L., \& Lockwood, C. M. (2000). Equivalence of the mediation, confounding and suppression effect. Prevention Science, 1(4), 173-181. doi:10.1023/A: 1026595011371

MacKinnon, D. P., Fairchild, A. J., \& Fritz, M. S. (2007). Mediation analysis. Annual Review of Psychology, 58, 593-614. doi:10. 1146/annurev.psych.58.110405.085542

Magen, Z., \& Aharoni, R. (1991). Adolescents' contributing toward others. Journal of Humanistic Psychology, 31(2), 126-143. doi: 10.1177/0022167891312015

Marsh, H. W., Byrne, B. M., \& Craven, R. (1992). Overcoming problems in confirmatory factor analyses of MTMM data: The correlated uniqueness model and factorial invariance. Multivariate Behavioral Research, 27(4), 489-507. doi:10.1207/s15327906mbr2704_1

Marta, E., \& Pozzi, M. (2008). Young people and volunteerism: A model of sustained volunteerism during the transition to adulthood. Journal of Adult Development, 15(1), 35-46. doi:10.1007/ s10804-007-9033-4

Marzana, D., Marta, E., \& Pozzi, M. (2012). Social action in young adults: Voluntary and political engagement. Journal of Adolescence, 35(3), 497-507. doi:10.1016/j.adolescence.2011. 08.013

McIntosh, H., Metz, E., \& Youniss, J. (2005). Community service and identity formation in adolescence. In J. L. Mahoney, R. W. Larson \& J. S. Eccles (Eds.), Organized activities as contexts of development (pp. 331-352). Mahwah, NJ: Lawrence Erlbaum Association.

Metz, E., McLellan, J. A., \& Youniss, J. (2003). Types of voluntary service and adolescents civic development. Journal of Adolescent Research, 18(2), 188-203. doi:10.1177/0743558402250350

Muthén, B., \& Muthén, L. (2010). Mplus (Version 6.1). Los Angeles, CA: StatModel.

Penner, L. A. (2004). Volunteerism and social problems: Making things better or worse? Journal of Social Issues, 60(3), 645-666. doi:10. 1111/j.0022-4537.2004.00377.x

Penner, L. A., \& Finkelstein, M. A. (1998). Dispositional and structural determinants of volunteerism. Journal of Personality and Social Psychology, 74(2), 525-537. doi:10.1037/0022-3514.74. 2.525

Penner, L. A., Fritzsche, B. A., Craiger, J. P., \& Freifeld, T. R. (1995). Measuring the prosocial personality. In C. D. Butcher \& C. D.
Spielberger (Eds.), Advances in personality assessment (pp. 147-163). Hillsdale, NJ: Erlbaum.

Reinders, H. (2005). Jugend. Werte. Zukunft. Wertvorstellungen, Zukunftsperspektiven und soziales Engagement im Jugendalter [Youth. Values. Future. Value orientations, future time perspectives and community service among adolescents]. Stuttgart, Germany: Landesstiftung Baden-Württemberg.

Reinders, H. (2006). Freiwilligenarbeit und politische Engagementbereitschaft in der Adoleszenz [Voluntary work and the willingness of civic engagement during adolescence]. Zeitschrift für Erziehungswissenschaft, 9(4), 599-616. doi:10.1007/ s11618-006-0170-5

Reinders, H. (2014). Jugend. Engagement. Politische Sozialisation. Gemeinnützige Tätigkeit und Persönlichkeitsentwicklung in der Adoleszenz [Community Service and Identity Development in Adolescence]. Wiesbaden, Germany: VS Verlag.

Reinders, H., \& Youniss, J. (2006). School-based required community service and civic development in adolescents. Applied Developmental Science, 10(1), 2-12. doi:10.1207/s1532480xads1001_1

Picot, S., \& Geiss, S. (2007). Freiwilliges Engagement Jugendlicher Daten und Fakten [Voluntary engagement in adolescence - Data and Facts]. Expertise zum Carl Bertelsmann-Preis 2007. Gütersloh, Germany: Bertelsmann-Stiftung.

Rogosa, D. R. (1995). Myths and methods: "Myths about longitudinal research". In J. M. Gottman (Ed.), The analysis of change (pp. 3-65). Mahwah, NJ: Lawrence Erlbaum Associates.

Scales, P. C., Blyth, D. A., Berkas, T. H., \& Kielsmeier, J. C. (2000). The effects of service-learning on middle school students' social responsibility and academic success. The Journal of Early Adolescence, 20(3), 332-358. doi:10.1177/ 0272431600020003004

Scales, P. C., Roehlkepartain, E. C., Neal, M., Kielsmeier, J. C., \& Benson, P. L. (2006). Reducing academic achievement gaps: The role of community service and service-learning. Journal of Experiential Education, 29(1), 38-60. doi: 10.1177/ 105382590602900105

Sherrod, L. R. (2007). Civic engagement as an expression of positive youth development. In R. K. Silbereisen \& R. M. Lerner (Eds.), Approaches to positive youth development (Vol. 1, pp. 59-74). London, UK: SAGE.

Shrout, P. E., \& Bolger, N. (2002). Mediation in experimental and nonexperimental studies: New procedures and recommendations. Psychological Methods, 7(4), 422-455. doi:10.1037/1082-989X.7. 4.422

Snyder, M., \& Omoto, A. M. (2007). Social action. In A. W. Kruglanski \& E. T. Higgins (Eds.), Social psychology: A handbook of basic principles (pp. 940-961). New York, NY: Guilford.

Steyer, R., Partchev, I., \& Shanahan, M. (2000). Modeling true intra-individual change in structural equation models: The case of poverty and children's psychosocial adjustment. In T. D. Little, K. U. Schnabel \& J. Baumert (Eds.), Modeling longitudinal and multiple-group data: Practical issues, applied approaches, and specific examples (pp. 109-126). Hillsdale, NJ: Erlbaum.

Watkins, N. D., Larson, R. W., \& Sullivan, P. J. (2007). Bridging intergroup difference in a community youth program. American Behavioral Scientist, 51(3), 380-402. doi: 10.1177/ 0002764207306066

Wilson, J., \& Musick, M. (1997). Who cares? Toward an integrated theory of volunteer work. American Sociological Review 62(5), 694-713. doi: $10.2307 / 2657355$ 
Yates, M., \& Youniss, J. (1996). A developmental perspective on community service. Social Development, 5(1), 85-111. doi: 10.1111/j. 1467-9507.1996.tb00073.x

Yates, M., \& Youniss, J. (1998). Community service and political identity development in adolescence. Journal of Social Issues, 54(3), 495-512. doi:10.1111/j.1540-4560.1998.tb01232.x

Youniss, J., \& Reinders, H. (2010). Youth and community service. Zeitschrift für Erziehungswissenschaft, 13(2), 233-248. doi:10. 1007/s11618-010-0122-y

Youniss, J., \& Yates, M. (1997). Community service and social responsibility in youth. Chicago, IL: The University of Chicago Press.

\section{Appendix}

Examples of community service activities:

- Humanitarian or environmental organizations, e.g. Greenpeace, work in a local animal shelter

- Clubs, e.g. trainer in a sports club (football, equitation, dancing)

- Church or religious institute, e.g. altar bay/girl, Church-run charity organization (Caritas, Malteser)

- Political party or trade union, e.g. youth organizations of German political parties (Junge Union, Grüne Jugend, Junge Sozialisten)

- Projects or initiatives, e.g. organizing local charity events (collecting money, cloths, toys, books during a charity event to support a local establishment; helping to repair a playground)

- Technical organization e.g. voluntary fire service, technical public aid (THW)

- Clinical or caring, e.g. visiting old or ill persons (regularly), Red Cross, helping disabled persons

- School, e.g. helping with IT support or in library, preparing school events,
Table AI. Full item list.

\section{Agency experiences}

Through my community service /free time activities, I have the feeling that ...

... I can make a contribution.

... I can make a difference.

... I can help other people.

... my work is useful.

... I do something worthwhile.

... I can change something.

Ideology experiences

Through my community service /free time activities ...

... my beliefs and opinions have changed.

... I have learned new things.

... I have achieved things that I would not have thought before.

... the view of myself has changed.

... I see myself in a different way.

... I see myself (my role) from a different point of view.

Prosocial behavior

I help people in need, when I see that they need help.

I help strangers, if they get lost.

I help old people to cross the street.

I help others by getting off the train or the bus if that person does not get it alone.

I would help another person, if the person falls off the bike.

I would help another person, if the person's shopping bag burst.

Note. Based on the information of being engaged in community service, adolescents were asked for their agency and ideology experience by using either the statement "Through my voluntary service" (for adolescents identified as engaged) or the statement "Through my free time activity" (for adolescents identified not engaged). In the computer-based telephone interviews, only the groupspecific phrase was used. 